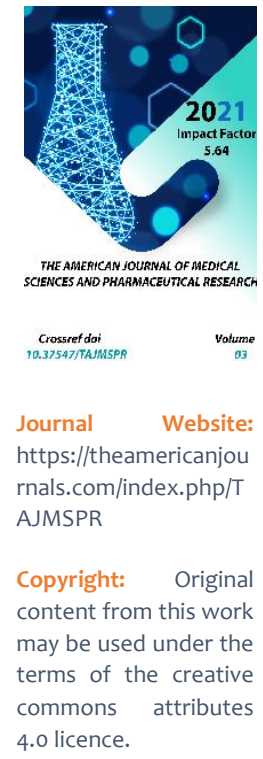

\title{
Clinical And Epidemiological Assessment And Causes Of Mortality From COVID-19 Coronavirus Infection (Literature Review)
}

Haitov Abdulaziz Haydar O'g'li

Assistant, Department Of Management, Public Health Bukhara State, Medical Institute, Bukhara, Uzbekistan

\section{ABSTRACT}

This literature review describes an analysis of the epidemic process associated with COVID-19 and presents possible scenarios. The most common anamnestic findings, symptoms of infection, clinical presentation, and possible complications are described in sufficient detail. The features of the course of COVID-19 in risk groups and algorithms of administrative and medical actions, which should form the basis of medical care for patients with cardiovascular, oncological, rheumatological diseases, pregnant women, etc., are highlighted.

\section{KEYWORDS}

Coronavirus infection, COVID-19, epidemiology, clinic, diagnosis, testing, PCR, comorbidities, risk groups.

\section{INTRODUCTION}

After several months of the epidemic process, it is natural for experts to predict and model pandemic development in different regions of the world where there are demographic, social, health and other differences that significantly affect the incidence of COVID-19. At the time of writing, about a dozen leading countries on the planet have emerged, including China, Italy, Spain, Germany, the
United Kingdom, the United States, and others. Despite the various anti-epidemic measures that have been taken, there is a further spread of the infection, involving more and more countries, which confirms the pandemic status given by the $\mathrm{WHO}[1,7]$.

Several possible options for the further course of the COVID-19 epidemic are discussed: 
- Active spread with the expansion of space and people involved, similar to virulent forms of influenza (examples of Spanish influenza, Hong Kong influenza, etc.),

- the epidemic subsides within a few months,

- a fluctuating course within specific infected areas,

- the development of an epidemic following a known, similar scenario, e.g. Chinese, Italian, American,

Mixed models based on territorial, geographical, ethnic and other differences,

- An abortive course, following the example of MERS and SARS coronavirus infections [2]. All epidemiologists and probably most people in the world are monitoring the course of the epidemic in their own and other territories, especially China, hoping for a favourable course of COVID-19.

However, following reassuring reports from China, cinemas in Shanghai have closed again after 18 days of operation and additional restrictive methods are being imposed, seriously alarming residents. Hong Kong and Singapore also fear a new wave of coronavirus. Following the discovery of new cases, foreigners have been banned from entering there and quarantine has been imposed on visiting locals [3].

Inevitably, events associated with the widespread SARS-CoV-2 will affect countries whose governments will have to balance sustaining their economies with controlling the spread of the virus. However, it should be noted that some countries do not impose restrictive measures, even in Europe, which threatens to form prolonged pockets of COVID-19 epidemics. However, the calculation is that this "non-intervention" could last for around a year until a vaccine has been developed, or until the majority of the world's population has been infected by COVID-19. Both pathways have their limitations. The former because of its sheer scale and high human toll, and the latter because of the uncertain prospects of creating a vaccine for a mutant RNA-containing virus. It should be recalled that, for a number of reasons, no vaccine has been created for the closely related respiratory syndrome viruses MERS and SARS, despite the considerable investment made $[5,8]$.

Although China has declared the end of the COVID-19 epidemic in its territory, the risk of a second wave persists. There are tensions in the country that the situation in Wuhan could repeat itself once the quarantine measures have been lifted. The situation in China is being closely monitored by other countries, as they could find themselves in the same situation in a few months' time. The measures being taken in China may seem excessive, given that not even a dozen cases of COVID-19 have been found in Jia, but the authorities do not want to repeat their mistakes. In the early stages of the coronavirus epidemic in Hubei province (as in most European countries), the scale of the problem was not adequately assessed and countermeasures were taken too late. The same problem is faced by other Asian countries that managed to contain the initial spread of the coronavirus: South Korea, Singapore and the Chinese autonomous territories of Taiwan and Hong Kong [3,12].

Researchers in Dr Kishi Prem's group at the London School of Hygiene \& Tropical Medicine have suggested that if the quarantine was lifted prematurely in March, a second wave of the epidemic could have occurred in China as early as late August. In some of the worst- 
affected countries in Europe, COVID-19 is expected to peak. The first preconditions for this are already in Italy and possibly in Spain. The countries with lower incidence are waiting tensely for developments, trying to make some adjustments to the administrative decisions taken. The hope of escaping the epidemic makes no sense because of the dispersion of infected people across the continent $[4,15]$. Russia is just entering the epidemic and does not yet know the possible scenarios of the process, continuing to evacuate compatriots from countries with high disease incidence, which will increase the number of COVID-19 patients, especially in Moscow, St. Petersburg and other big cities. In parallel, territories are imposing restrictive measures on Russian citizens moving across administrative boundaries without proper justification. However, it has already been noted that the flow of hospitalised patients is mainly due to infections in our country. Indications for hospitalisation are gradually limited to cases with clinical manifestations and the possibility of complications during the course of the disease. Adjustments in isolation and hospitalisation conditions are likely, taking into account regional capacities and other territorial factors [5]. At the same time, the flow of hospitalised patients in domestic infectious diseases and adapted hospitals is increasing and an increasing number of trained infectious disease doctors, pulmonologists and intensive care specialists are required. The contingents of these patients are diverse in age, from newborns to the elderly with a variety of comorbidities. Today, doctors rely on the published experience of their foreign colleagues, which differs in treatment results between Asian and European countries in favour of the former. The US and European countries are ahead of other regions of the world in terms of prevalence, a number of patients with an active course and severe cases[1,19]. Against this background Russia looks favourably so far in terms of COVID-19 cases (about 6.5 thousand), mortality (only about 60 people at the time of writing - first week of April) and the number of people who have recovered (about 400-500). However, the daily increase in incidence, commensurate with the leaders of the top three countries, is an alarming manifestation of the epidemic process [6].

Anamnesis, symptoms of infection, clinical presentation and possible complications. The manifestations of the COVID-19 outbreak have varied clinically from asymptomatic mild symptoms to severe illness and extreme morbidity with fatal outcomes. Symptoms may include fever, cough and shortness of breath and other non-specific manifestations. [7, 8, 9]. Wu et al. reported that among 72000 cases of COVID-19 reported to the Chinese Centre for Disease Control and Prevention, 81\% were mild (no or focal pneumonia), $14 \%$ were severe (hypoxia, dyspnoea, involvement of more than half the lungs within 24-48 hours), 5\% were critical (Respiratory Distress Syndrome, shock, respiratory failure, multiple organ dysfunction) and $2.3 \%$ were fatal [10].

The main clinical manifestations of the infectious process include:

- $\quad$ High fever over $38^{\circ} \mathrm{C}(90 \%)$;

- $\quad$ Cough, dry or with little sputum (80\%);

- Hypnoea with respiratory rate $>22$ per $\min (55 \%)$;

- $\quad$ Myalgias, fatigue, weakness (44\%);

- $\quad$ Chest Congestion (>20\%);

- $\quad$ Confusion (9\%);

- $\quad$ Headaches (8\%);

- $\quad$ Hemoptysis (5\%); 


- Gastrointestinal symptoms, which
included anorexia ( $83.8 \%$ of cases),
Diarrhoea (3 to $29 \%$ of cases);
- $\quad$ Vomiting ( $0.8 \%$ of cases); and
abdominal pain ( $0.4 \%$ of cases).

In this part of the surveillance, the mortality rate from COVID-19 ranges from $5.8 \%$ in Wuhan to $0.7 \%$ in the rest of China [11]. Most deaths occur in patients who are elderly or have comorbidities (e.g. diabetes, cardiovascular disease, chronic lung disease, cancer, arterial hypertension and some others) [12]. These differences between territories need to be explained at the end of the epidemic. Symptoms in children with infection appear to be rare, although some children with severe COVID-19 have been reported (10). Risk factors for an unfavourable course of the disease in children included a pre-morbid background (lung disease, Kawasaki disease), immunodeficiency conditions of different genesis (children $>5$ years of age are more likely to become ill; pneumonia is 1.5 times more common), and coinfection with the respiratory syncytial virus. Asymptomatic infections have been reported, but their frequency is unknown (13). The study also observed associations between the presence of symptoms and the severity of COVID-19. For example, gastrointestinal symptoms became more pronounced as COVID-19 severity increased, and patients were less likely to be cured and discharged compared to those without symptoms $(34.3 \%$ versus $60 \%$, respectively).

\section{The course of COVID-19 in at-risk groups and an algorithm for action}

According to continuously published reports and surveys, about $1 / 3$ of the population in developed countries are at higher risk of serious disease if they are infected with COVID19. A group of researchers in the United States estimated that 105.5 million people in the United States are at high risk of serious disease if infected, including $\mathbf{2 9 . 2}$ million adults under 60 years of age due to underlying disease and 76.3 million adults aged 60 and over [14]. One group at particular risk is people living in nursing homes [15], who are at higher risk of serious illness if infected with coronavirus, confirming the need for unprecedented efforts to minimize its spread. Although, in general, most infected people do not develop symptoms of the disease and many of that infected recover quickly without needing treatment, according to the World Health Organization [16], 41\% (105.5 million/258 million in 2018) of US adults are at high risk of serious illness if they are infected with the new coronavirus [14]. The researchers defined 'high risk', using the latest information from the CDC, as adults aged 60 and over and young people aged 18 to 59 with cancer, cardiovascular disease, chronic obstructive pulmonary disease or cf[fhysv diabetes. According to the American Heart Association [17], about 1 in 3 American adults has high blood pressure, which is an additional risk factor. The majority of these patients live in large, industrialised cities, metropolitan areas, ranging from $31 \%$ to $51 \%$ In US cities and regions such as Washington, California and New York, the cities most affected by COVID-19 so far, have a $40 \%, 37 \%$ and $40 \%$ proportion of adults at high risk, respectively. In developed countries (USA, Italy, Spain, etc.), estimates vary for about 40\% of the total population at high risk of serious diseases. Of the 105.5 million people at high risk in the USA, 76.3 million are aged $\geq 60$ years and 29.2 million are younger, at a younger age, but with co-morbidities [14]. The Italian National Institute of Health (Istituto Superiore di 
Sanitarium) has published a report describing patients who died of COVID-19. Records of 6,801 patients were analysed, and the average age of those who died of COVID-19 in Italy was
78 years. The number of comorbidities was assessed in 710 deceased patients (Table 1).

Table 1. The Italian National Institute of Health (Istituto Superiore di Sanitarium) has published a report describing patients who died of COVID-19.

\begin{tabular}{|c|c|c|}
\hline Disease & Number of patients & $\%$ \\
\hline Atrial fibrillation & 249 & $\mathbf{2 7 , 8}$ \\
\hline Heart failure & 213 & $\mathbf{2 3 , 7}$ \\
\hline Stroke & 153 & $\mathbf{1 7 , 1}$ \\
\hline Arterial hypertension & 101 & $\mathbf{1 1 , 3}$ \\
\hline Diabetes mellitus & 655 & $\mathbf{7 3 , 0}$ \\
\hline Dementia & 281 & $\mathbf{3 1 , 3}$ \\
\hline COPD & 130 & $\mathbf{1 4 , 5}$ \\
\hline Active cancer within the last five years & 150 & $\mathbf{1 6 , 7}$ \\
\hline Chronic kidney disease & 155 & $\mathbf{1 7 , 3}$ \\
\hline \hline Chronic renal failure & 37 & $\mathbf{4 , 1}$ \\
\hline \hline
\end{tabular}

Only 15 of them had no chronic diseases. Half of those who died of coronavirus infection had three or more pathologies - 360 patients (50.7\%). Two comorbidities were present in 184 patients (25.9\%) and one in 151 patients (21.3\%). [18]. Another viewpoint, based on real clinical practice, has emerged. The high mortality from
COVID-19 in Italy may indicate limited coverage of testing for infection compared to countries such as China and Korea. The study analysed patients from all Italian regions as of 17.03.2020. The mortality rate from COVID-19 was found to be $7.2 \%$ (1,625 deaths per 22,512 cases). This rate appeared to be the main factor (Table 2). 
Table 2. Reasons for high mortality associated with COVID-19 in Italian patients

\begin{tabular}{|c|c|}
\hline Indicator & Commentary \\
\hline & $\begin{array}{l}\text { The demographics of Italy's population differ from those of other countries. In } \\
\text { 2019, about } 23 \% \text { of Italians were aged } \geq 65 \text { years } \\
\text { - Lethality from COVID-19 reached } 7.2 \% \text { in Italy and only } 2.3 \% \text { in China. } \\
\text { Distribution by age group: in patients under } 69 \text { years of age the rate is similar } \\
\text { for both countries, in older patients it is higher in Italy, especially in the group } \\
\text { over } 80 \text { years of age. } \\
\text { - Italy has a high number of COVID-19 cases in the group } \geq 90 \text { years ( } 687 \\
\text { patients), with a very high mortality rate (up to } 22.7 \% \text { ). In China, no COVID-19 } \\
\text { cases have been reported in this age group. }\end{array}$ \\
\hline Age & $\begin{array}{l}\text { - The criteria for classifying deaths as COVID-19 victims have not yet been } \\
\text { established internationally and may vary from country to country. } \\
\text { - In Italy, the criterion is the death of a patient who tested positive for SARS- } \\
\text { CoV-2 using PCR, regardless of the co-morbidities that could have caused the } \\
\text { death. } \\
\text { - Such an approach may have led to an overestimation of the mortality rate. In } \\
\text { Italy, in a sample of } 355 \text { patients who died with COVID-19, almost } 1 / 2 \text { had three } \\
\text { or more serious comorbidities and about } 1 / 4 \text { had two comorbidities that could } \\
\text { have led to death regardless of the presence of coronavirus infection. }\end{array}$ \\
\hline $\begin{array}{l}\text { Population } \\
\text { testing for } \\
\text { coronavirus }\end{array}$ & 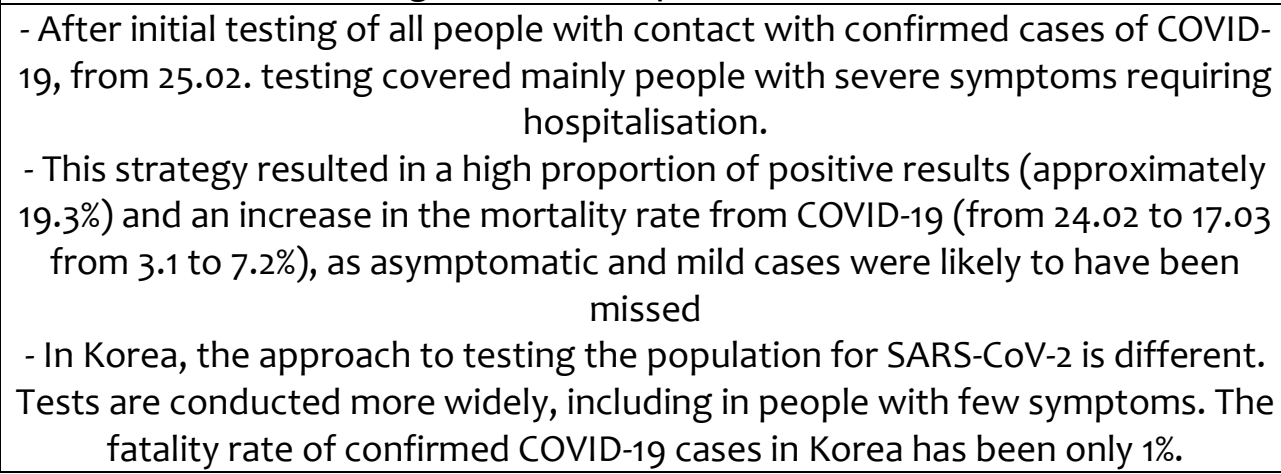 \\
\hline
\end{tabular}

These and subsequent studies have shown the important role of comorbid conditions in COVID-19 outcomes.

\section{CONCLUSION}

In summary, an understanding is emerging of the seriousness of the demographic, social and health consequences of the pandemic COVID19 , a set of tentative directions and approaches in assessing the results of epidemiological, diagnostic and treatment interventions in general.
Populations and leaders, with few exceptions, have understood the importance and danger of this new epidemic for the advancement of civilization. Its impact extends beyond the medical aspects to economics, politics, industry and others. Most countries responded or had to submit to strict restrictive or quarantine measures. China's experience has shown that it is possible to maintain a psychologically tolerable environment for most people in isolation. However, governments are aware of the tensions in a 
number of countries and the risk of destabilising order. The large number of people cured and the declining case-fatality rate give grounds for a positive view of the prospect of recovery from the pandemic. At the same time, there is an emerging awareness of the need to re-engineer sanitation and health services, given the risk of new epidemics in the face of climate and environmental change. Part three of the review will examine preventive and curative measures against the emerging pandemic coronavirus infection.

\section{REFERENCES}

1. Temporary guidelines of the Ministry of Health of the Russian Federation "Prevention, diagnosis and treatment of new coronavirus infection (COVID19)" Version 5. 08.04.2020.

2. CDC. 2019 Novel Coronavirus, Wuhan, China: Symptoms. CDC. Available at https://www.cdc.gov/coronavirus/2019 -ncov/about/symptoms.html. January 26, 2020; Accessed: January 27, 2020.

3. Hui, D. S., Azhar, E. I., Madani, T. A., Ntoumi, F., Kock, R., Dar, O., ... \& Petersen, E. (2020). The continuing 2019-nCoV epidemic threat of novel coronaviruses to global health-The latest 2019 novel coronavirus outbreak in Wuhan, China. International Journal of infectious diseases, 91, 264-266.

4. Lauer, S. A., Grantz, K. H., Bi, Q., Jones, F. K., Zheng, Q., Meredith, H. R., ... \& Lessler, J. (2020). The incubation period of coronavirus disease 2019 (COVID-19) from publicly reported confirmed cases: estimation and application. Annals of internal medicine, 172(9), 577-582.

5. Wu, Z., \& McGoogan, J. M. (2020). Characteristics of and important lessons from the coronavirus disease 2019 (COVID-19) outbreak in China: summary of a report of 72314 cases from the Chinese Center for Disease Control and Prevention. Jama, 323(13), 1239-1242.

6. Report of the WHO-China Joint Mission on Coronavirus Disease 2019 (COVID19). Available at http://www.who.int/docs/defaultsource/coronaviruse/who-china-jointmission-on-covid- 19-final-report.pdf. February 16-24, 2020; Accessed: March 04, 2020.

7. Zhou, F., Yu, T., Du, R., Fan, G., Liu, Y., Liu, Z., ... \& Cao, B. (2020). Clinical course and risk factors for mortality of adult inpatients with COVID-19 in Wuhan, China: a retrospective cohort study. The lancet, 395(10229), 10541062.

8. Chan, J. F. W., Yuan, S., Kok, K. H., To, K. K. W., Chu, H., Yang, J., ... \& Yuen, K. Y. (2020). A familial cluster of pneumonia associated with the 2019 novel coronavirus indicating person-toperson transmission: a study of a family cluster. The lancet, 395(10223), 514-523.

9. Ilkhomovna, K. M., Eriyigitovich, I. S., \& Kadyrovich, K. N. (2020). Morphological Features of Microvascular Tissue of The Brain At Hemorrhagic Stroke. The American Journal of Medical Sciences and Pharmaceutical Research, 2(10), 53-59.

10. Kamalova, M. I., Khaidarov, N. K., \& Islamov, S. E. (2020). Pathomorphological Features of hemorrhagic brain strokes. Journal of Biomedicine and Practice, 101-105.

11. Kadyrovich, K. N., Erkinovich, S. K., \& Ilhomovna, K. M. (2021). Microscopic 
Examination Of Postcapillary Cerebral Venues In Hemorrhagic Stroke. The American Journal of Medical Sciences and Pharmaceutical Research, 3(08), 69-73.

12. Shomurodov K.E. (2010). Peculiarities of cytokine balance in gingival fluid at odontogenicphlegmon of the maxillofacial area. The doctor-aspirant. 42(5.1). - C. 187-192.

13. Isomov M.M., Shomurodov K.E. (2020). Peculiarities of rehabilitation of pregnant women with inflammatory diseases of maxillofacial area. International scientific-practical conference "Modern aspects of complex dental rehabilitation of patients with maxillofacial defects" May 21-22, 2020, C. 72-76.

14. Updates, C. L. (2020). WHO Declares pandemic as number of infected countries Grows. The New York Times.

15. https://ui.adsa bs.harvard.edu/abs/2020arXiv2003098 $\mathrm{ooH} / \mathrm{abstract}$.

16. https://news.ru/asia/kitayu-grozitvtoraya-volna-epidemii-covid-19/.

17. https://www.who.int/emergencies/dis eases/novel-coronavirus-2019.

18. Ismoilov, O. I., Murodkosimov, S. M., Kamalova, M. I., Turaev, A. Y., \& Mahmudova, S. K. (2021). The Spread Of SARS-Cov-2 Coronavirus In Uzbekistan And Current Response Measures. The American Journal of Medical Sciences and Pharmaceutical Research, 3(03), 45-50. 